\title{
DETERMINAÇÃO DE PARÂMETROS FÍSICO-QUÍMICOS E DA CONCENTRAÇÃO DE METAIS EM MÉIS DE DIFERENTES REGIÕES BRASILEIRAS
}

\section{DETERMINATION OF PHYSICOCHEMICAL PARAMETERS AND METALS CONCENTRATION IN HONEYS FROM DIFFERENT BRAZILIAN REGIONS}

\author{
Aline Dalavia de Jesus ${ }^{1}$; Odenel Moreira Castilho Júnior ${ }^{1}$, Bárbara Spessoto Martinez ${ }^{2}$; Adriana dos \\ Santos da Silva², Adriana Paiva de Oliveira ${ }^{1,3}$ \\ ${ }^{1}$ Universidade de Cuiabá - UNIC - Cuiabá - Brasil alinedalavia@ hotmail.com \\ ${ }^{2}$ Universidade Federal de Mato Grosso - UFMT - Cuiabá - Brasil \\ ${ }^{3}$ Instituto Federal de Educação, Ciência e Tecnologia de Mato Grosso - Campus Cuiabá - Bela \\ Vista - IFMT - Cuiabá - Brasil dri_poliv@ig.com.br
}

\begin{abstract}
Resumo
Este trabalho teve como objetivo a determinação de parâmetros físico-químicos e da concentração de metais em méis produzidos em diferentes regiões do Brasil e a comparação dos resultados com a Legislação vigente. Para este propósito, sete amostras de diferentes regiões do Brasil foram coletadas $e$ as seguintes determinações feitas: $\mathrm{Na}, \mathrm{K}, \mathrm{Mg}, \mathrm{Mn}, \mathrm{Zn}, \mathrm{Cu}$, umidade, cinzas, condutividade elétrica, acidez livre, atividade diastásica, reações de Lund, Fiehe e Lugol. A acidez. livre, o teor de umidade e cinzas e a atividade diastática de estão de acordo com as especificações requeridas pela Legislação Brasileira. No teste de Lugol, todas as amostras apresentaram resultados positivos, ou seja, foram detectadas a presença de dextrinas e amido. Na reação de Fiehe, cinco amostras obtiveram resultados positivos indicando o superaquecimento elou presença de xaropes de açúcar. Os testes de Lund apresentaram resultado positivo indicando a presença de albuminóides. Para todas as amostras, as concentrações dos metais estão de acordo com os valores permitidos pela Legislação e literatura para méis. Neste contexto, os resultados sugerem que a produção do mel no Brasil precisa ser acompanhada de uma rígida fiscalização e controle de qualidade para garantir um produto livre de adulterações, fraudes e contaminações.
\end{abstract}

Palavras-chave: mel; parâmetros físico-químicos; metais.

\section{Introdução}

O mel é considerado um fluido viscoso, aromático e doce, elaborado pelas abelhas a partir do néctar das flores e/ou exsudações sacarínicas de partes vivas das plantas, podendo ainda ser proveniente das excreções de insetos sugadores que se alimentam de partes vivas das plantas. Estes 
produtos, depois de coletados, transformados e combinados com substâncias específicas próprias, são armazenados e amadurecidos nos favos para a alimentação das abelhas (MENDES; COELHO; BRASIL, 2000).

A composição do mel depende, principalmente, das fontes vegetais das quais ele é derivado, mas também do tempo, solo, espécie da abelha, estado fisiológico da colônia, estado de maturação do mel, condições meteorológicas na época da colheita, dentre outros fatores (CRANE, 1983).

A elaboração do mel resulta de duas modificações principais (reações) sofridas pelo néctar, uma física pela desidratação (eliminação da água), através da evaporação na colméia e absorção no papo, a outra que atua sobre o néctar, transformando a sacarose, através da enzima invertase, em glicose e frutose. Ocorrem mais duas reações, em escala menor, que consistem em transformar o amido do néctar, através da enzima amilase em maltose e a enzima glicose-oxidase que transforma a glicose em ácido glicônico e peróxido de hidrogênio, este último, conhecido como água oxigenada (CRANE, 1983).

Como há uma grande variação na flora a coloração, sabor, aroma e consistência do mel apresentam diferentes características. Relacionando a flora com a cor, o mel pode variar do branco, amarelo e tonalidades âmbares (ARRUDA et al., 2004).

As análises físico-químicas contribuem na fiscalização e no controle da qualidade do mel produzido. Os resultados são comparados com os padrões oficiais internacionais e com os estabelecidos pelo próprio país, protegendo o consumidor de adquirir um produto adulterado ou de baixa qualidade (ARRUDA et al., 2004). No Brasil, o mel deve seguir os parâmetros estabelecidos pelo Ministério do Abastecimento, Pecuária e Agricultura (MAPA) para o controle de qualidade (BRASIL, 2000).

A avaliação dos constituintes do mel é necessária, uma vez que estes influenciam a qualidade durante a estocagem, a cristalização, a textura, o aroma e a qualidade nutricional (ALVES, 2005). No processo produtivo do mel é comum encontrar variações na sua composição física e química, tendo em vista que variados fatores interferem na sua qualidade, como condições climáticas, estádio de maturação, espécie de abelha, processamento e armazenamento, além do tipo de florada (SILVA et al., 2004).

Frente ao exposto, o presente trabalho teve como objetivo a determinação de parâmetros físico-químicos e da concentração de espécies metálicas em amostras de méis produzidas em diferentes regiões brasileiras. 


\section{Material e métodos}

Sete amostras de méis foram coletadas no $18^{\circ}$ Congresso Brasileiro de Apicultura e $4^{\circ}$ Congresso de Meliponicultura realizados em Cuiabá- MT no período de 19 a 22 de maio de 2010, sendo três amostras oriundas da região Centro-Oeste (CO), uma da região do Nordeste (NO), uma da região Sul (S), uma da região Norte $(\mathrm{N})$ e uma da região Sudeste (SD).

As amostras encontravam-se envasadas em frascos de vidro ou plástico de peso total de $450 \mathrm{~g}$ e permaneceram sob-refrigeração até a análise. Todas as amostras foram analisadas dentro do prazo de validade constante do rótulo e identificadas como: A1 (N), A2 (CO), A3 (CO), A4 (S), A5 (NO), A6 (SD) e A7 (CO).

Para todas as determinações foram utilizadas vidrarias comuns a um laboratório de análises de alimentos, reagentes químicos e sistemas de gases com qualidade necessários para a determinação dos parâmetros físico-químicos propostos no trabalho.

\section{Determinação da acidez livre}

O mel contém ácidos que contribuem para sua estabilidade frente ao desenvolvimento de microrganismos. Dentre os ácidos encontrados nos méis, o mais comum é o glucônico que é formada pela ação da enzima glicose-oxidase produzida pelas glândulas hipofaringeanas das abelhas. Todos os outros ácidos (acético, benzóico, butírico, cítrico, fenilacético, fórmico, isovalérico, láctico, maléico, oxálico, propiônico, piroglutânico, succínico e valérico) estão presentes em quantidades menores (CRANE, 1983). Estes ácidos estão dissolvidos em solução aquosa no mel e produzem íons $\mathrm{H}^{+}$que promovem a sua acidez ativa permitindo, assim, indicar as condições de armazenamento e o processo de fermentação.

Para a determinação da acidez livre, $10 \mathrm{~g}$ da amostra foram pesados em balança analítica $\left(\right.$ GEHAKA $^{\circledR}$, modelo AG -200) em um béquer de $250 \mathrm{~mL}$ e dissolvidos com $75 \mathrm{~mL}$ de água e homogeinizados. Posteriormente, o eletrodo de vidro de um pHmetro digital marca QUIMIS ${ }^{\circledR}$ modelo Q - 400A já calibrado foi mergulhado na solução e o valor do pH inicial foi medido. Em seguida a solução contendo a amostra foi titulada com uma solução padrão de $\mathrm{NaOH} 0,05 \mathrm{~N}$ até pH 8,5. O branco analítico foi obtido por meio da titulação de $75 \mathrm{~mL}$ de água com $\mathrm{NaOH} 0,05 \mathrm{~N}$ até pH 8,5 (CANO, 2005).

\section{Determinação de cinzas}

O teor de cinzas expressa os minerais presentes no mel, o qual é bastante utilizado na verificação da qualidade do produto. Os sais minerais encontrados no mel podem ser modificados por fatores relativos às abelhas, ao apicultor, clima, solo e origem botânica (LASCEVE e 
GONNET; BOGDANOV, 1999; ALVES et al.). Assim, o mel de origem floral tem menos cinzas que o mel de origem não floral (BOGDANOV, 1999).

Este procedimento feito por meio da medida de massa de $5 \mathrm{~g}$ de mel em um cadinho de porcelana tarado. Em seguida, a amostra foi incinerada à temperatura de $450^{\circ} \mathrm{C}$ em forno mufla, marca QUIMIS modelo Q318-M24, até que se obtenha resíduo branco (cerca de três horas). O cadinho foi pesado novamente com as cinzas (CANO, 2005).

\section{Determinação de umidade}

$\mathrm{Na}$ composição do mel, a água constitui o segundo componente em quantidade, geralmente variando de 15 a $21 \%$, dependendo do clima, origem floral e colheita antes da completa desidratação. O conteúdo de água no mel é, sem dúvida, uma das características mais importantes, por influenciar na sua viscosidade, peso específico, maturidade, cristalização, sabor, conservação e palatabilidade (MARCHINI et al.). Os microrganismos osmofílicos (tolerantes ao açúcar), presentes nos corpos das abelhas, no néctar, no solo, nas áreas de extração e armazenamento podem provocar fermentação no mel quando o teor de água for muito elevado (WHITE JÚNIOR, 1979; MARCHINI et al.). O mel é um alimento muito higroscópico, e pode facilmente absorver água, conforme as condições de armazenamento, manejo e região. Méis com teores mais elevados de umidade fermentam com certa facilidade. O mel deve apresentar no máximo $20 \mathrm{~g}$ de umidade/ 100g de mel analisado (BRASIL, 2000).

A determinação da umidade consistiu das seguintes etapas: em uma cápsula de porcelana foram pesadas $2,0 \mathrm{~g}$ de mel, e a mesma foi inserida em estufa para secagem a $110^{\circ} \mathrm{C}$ por 5 horas. Posteriormente, a cápsula de porcelana foi pesada, e calculada o teor de umidade.

\section{Condutividade elétrica}

A condutividade elétrica é uma característica importante na determinação da origem botânica do mel de abelhas (BOGDANOV et al.). A condutividade elétrica do mel é definida como aquela de uma solução aquosa $20 \%$ em peso a $20^{\circ} \mathrm{C}$ sendo que $20 \%$ se referem à matéria seca de mel. O procedimento consistiu na dissolução de $10 \mathrm{~g}$ de mel em $50 \mathrm{~mL}$ de água deionizada, e a leitura direta em um condutivímetro marca MICRONAL ${ }^{\circledR}$ modelo B330.

\section{Determinação da atividade diastásica}

A diastase é uma das enzimas do mel, que tem a função de digerir a molécula de amido, sendo muito sensível ao calor, podendo assim indicar o grau de conservação e superaquecimento do produto (WHITE JÚNIOR, 1994).

A ausência da mesma reflete procedimentos e/ou adulterações realizadas no mel, tal como uso de temperatura acima de $60^{\circ} \mathrm{C}$ durante o beneficiamento, adição de açúcar invertido, condições 
de armazenamento inadequadas (tempo acima de seis meses e temperaturas elevadas). A atividade diastásica diminui devido à desnaturação parcial ou total das amilases (AROUCHA et al.). A legislação permite atividade diastásica como mínimo oito na escala Göthe. Os méis com baixo conteúdo enzimático devem ter como mínimo uma atividade diastásica correspondente a três na escala Göthe, sempre que o conteúdo de HMF não exceda a $15 \mathrm{mg} \mathrm{kg}^{-1}$ (BRASIL, 2000).

Neste procedimento, $10 \mathrm{~g}$ de amostra foram dissolvidas com $15 \mathrm{~mL}$ de água, e adicionados 5 $\mathrm{mL}$ de solução tampão e transferidas para um balão volumétrico de $50 \mathrm{~mL}$, contendo $3 \mathrm{~mL}$ da solução de $\mathrm{NaCl}$ 0,5 M, e o volume do balão volumétrico foi completado até a marca de aferição com água deionizada. Em um tubo de ensaio contendo $10 \mathrm{~mL}$ desta solução de mel tamponada foram inseridos $5 \mathrm{~mL}$ de uma solução de amido e o tubo foi inserido em banho maria por 15 minutos. Em intervalos de 5 minutos, alíquotas de $1 \mathrm{~mL}$ desta solução foram pipetadas e adicionadas rapidamente em uma proveta de $50 \mathrm{~mL}+10 \mathrm{~mL}$ de solução de iodo $0,00035 \mathrm{M}$. A absorbância foi determinada em um espectrofotômetro marca BEL PHOTONICS ${ }^{\circledR}$ modelo 2000 UV a $660 \mathrm{~nm}$. Novas alíquotas de $1 \mathrm{~mL}$ foram tomadas em intervalos de 5 minutos, até obter um valor de absorbância menor que 0,235 (CANO, 2005).

\section{Reação de Lund}

A reação de Lund indica a presença de substâncias albuminóides, componentes normais no mel e que são precipitados pelo ácido tânico adicionado na amostra. Na presença de mel natural esse precipitado forma um depósito de 0,6 a 3,0 $\mathrm{mL}$ no fundo da proveta. No entanto, a reação não ocorre em mel artificial e, no caso de mel adulterado, o volume do precipitado aparecerá em menor quantidade (CANO, 2005).

Neste procedimento foram pesados 2,0 $\mathrm{g}$ de amostra que foram transferidas para uma proveta de $50 \mathrm{~mL}$ com tampa com o auxilio de $20 \mathrm{~mL}$ de água destilada. Posteriormente, foram adicionados $5 \mathrm{~mL}$ de solução de ácido tânico $0,5 \%(\mathrm{~m} / \mathrm{v})$ e água destilada até completar o volume de $40 \mathrm{~mL}$ sob agitação e a mistura permaneceu em repouso por $24 \mathrm{~h}$. Na presença de mel puro, será formado um precipitado no fundo da proveta no intervalo de 0,6 a 3,0 mL. Na presença de mel adulterado, não haverá formação de precipitado ou excederá o volume máximo do referido intervalo (CANO, 2005).

\section{Reação de Fiehe}

A presença de hidroximetilfurfural (HMF) pela reação de Fiehe indica adulterações no mel por xaropes e glicose comercial ou ainda superaquecimento (WIESE, 2000; PINTO e RUDGE).

Aproximadamente, $5 \mathrm{~g}$ de amostra foram pesados em um béquer de $50 \mathrm{~mL}$, e em seguida, adicionados $5 \mathrm{~mL}$ de éter etílico. Esta mistura foi agitada vigorosamente e a camada éterea foi transferida para um tubo de ensaio no qual foi adicionado $0,5 \mathrm{~mL}$ de uma solução clorídrica de 
resorcina e deixado em repouso por 10 minutos. A cor vermelha persistente indica positividade ou presença elevada de HMF (possivelmente mais de $200 \mathrm{mg} \mathrm{kg}^{-1}$ ) (LEAL et al.).

\section{Reação de Lugol}

Wiese (2000) constata que ao utilizar o iodo e iodeto de potássio (lugol), o mel adulterado apresenta reação colorida característica em função da presença de amido e dextrina, o que não ocorre no mel puro.

Neste procedimento, foram pesados $10 \mathrm{~g}$ da amostra em um béquer de $50 \mathrm{~mL}$ e adicionados $20 \mathrm{~mL}$ de água, em seguida a mistura foi agitada com bastão de vidro. A solução foi inserida em um banho-maria fervente por uma hora e em seguida resfriada à temperatura ambiente, e adicionados $0,5 \mathrm{~mL}$ da solução de Lugol. Na presença de glicose comercial ou xaropes de açúcar, a solução ficará colorida de marrom-avermelhada a azul (CANO, 2005).

\section{Determinação da concentração de metais}

O procedimento experimental consistiu na medida de massa de 1,25 g de amostra em seguida da adição de $1,25 \mathrm{~mL}$ de $\mathrm{HNO}_{3}$ e 2,5 mL de $\mathrm{H}_{2} \mathrm{O}_{2}$. Em seguida, as amostras foram sonicadas por 20 minutos em um banho ultrasônico QUIMIS ${ }^{\circledR}$ e o extrato obtido foi transferido para um balão volumétrico de $25 \mathrm{~mL}$ e diluído com água deionizada até a marca de aferição (LACERDA et.al.). A determinação das concentrações de $\mathrm{Na}, \mathrm{K}, \mathrm{Mg}, \mathrm{Zn}, \mathrm{Cu}$ e $\mathrm{Mn}$ foi feita no extrato das amostras empregando um espectrômetro de absorção atômica marca VARIAN ${ }^{\circledR}$ SPECTRAA 200. Todas as determinações foram feitas em triplicatas $(n=3)$ e acompanhadas de um branco analítico.

\section{Resultados e discussão}

Nos testes qualitativos, os resultados da reação de Lund foram positivos para todas as amostras analisadas, e estão de acordo com a legislação brasileira (BRASIL, 2000), indicando a presença de substâncias albuminóides. Na reação de Lugol todas as amostras sofreram modificação de cor, indicando a presença de dextrinas e amido. Na reação de Fiehe, 75\% das amostras obtiveram resultados positivos, sugerindo possíveis adulterações por xaropes e glicose comercial ou superaquecimento.

O valor da acidez livre de todas as amostras estão de acordo com as especificações da Legislação Brasileira que é de no máximo $50 \mathrm{mg} \mathrm{kg}^{-1}$ (Tabela 1). A acidez é um parâmetro que pode contribuir na avaliação do grau de deterioração do mel, além de auxiliar na diminuição do crescimento bacteriano e realçar o sabor do mesmo. 
TABELA 1 - Resultados das determinações dos parâmetros físico-químicos (média \pm desvio-padrão, $n=3$ ) obtidos nas amostras de méis diferentes regiões brasileiras.

\begin{tabular}{|c|c|c|c|c|c|c|c|c|}
\hline Amostra & $\begin{array}{c}\text { Umidade } \\
(\mathrm{g} / \mathbf{1 0 0 g})\end{array}$ & $\begin{array}{c}\text { Cinzas } \\
(\mathrm{g} / 100 \mathrm{~g})\end{array}$ & $\begin{array}{c}\mathrm{AD}^{* * 3} \\
\left(\mathrm{mg} \mathrm{kg}^{-1}\right)\end{array}$ & $\begin{array}{c}C E^{-1} \\
\left(\mu \mathrm{cm}^{-1}\right)\end{array}$ & $\begin{array}{c}\text { Acidez Livre } \\
\left.(\mathrm{meq} \mathrm{kg})^{-1}\right)\end{array}$ & Lugol & Fiehe & Lund \\
\hline$\overline{A 1}$ & $15,0 \pm 0,1$ & $0,53 \pm 0,01$ & $14,1 \pm 0,2$ & 374,5 & $30,0 \pm 0,5$ & $r$ & $\mathrm{P}^{* * * * * *}$ & $\mathrm{P}^{* * *}$ \\
\hline A2 & $18,5 \pm 0,4$ & $0,51 \pm 0,05$ & $14,5 \pm 0,1$ & 592 & $25,8 \pm 0,3$ & $\mathrm{P}^{* * * *}$ & $\mathrm{P}^{* * * * 6}$ & $\mathrm{P}^{* * \cdots * * *}$ \\
\hline A3 & $14,7 \pm 0,5$ & $0,52 \pm 0,05$ & $14,8 \pm 0,2$ & 493 & $33,7 \pm 0,3$ & $\mathrm{P}^{* * 3: 1}$ & $\mathrm{P}^{* * * * * *}$ & $\mathrm{P}^{* * \cdots * * *}$ \\
\hline A4 & $13,0 \pm 0,1$ & $0,51 \pm 0,02$ & $15,0 \pm 0,7$ & 1202 & $39,4 \pm 0,2$ & & & \\
\hline A5 & $16,9 \pm 0,7$ & $0,54 \pm 0,04$ & $15,0 \pm 0,1$ & 350,5 & $30,7 \pm 0,1$ & $\mathrm{P}^{* * 2}$ & $\mathrm{~N}^{*}$ & $\mathrm{P}^{* * *}$ \\
\hline A6 & $18,2 \pm 0,1$ & $0,53 \pm 0,03$ & $13,8 \pm 0,2$ & 901 & $37,1 \pm 0,2$ & $\mathrm{P}^{* * *}$ & $\mathrm{P}^{* * *}$ & $\mathrm{P}^{* * * \cdots}$ \\
\hline A7 & $18,6 \pm 0,4$ & $0,51 \pm 0,06$ & $14,9 \pm 0,3$ & 663,5 & $37,9 \pm 0,8$ & $\mathrm{P}^{* * * * *}$ & $\mathrm{P}^{* * * * *}$ & $\mathrm{P}^{* * *}$ \\
\hline $\mathbf{V M P}^{*}$ & 20 & 0,6 & 15 & $\mathrm{NE}$ & 50 & $\mathrm{~N}^{* * 2}$ & $\mathrm{~N}^{* * ;}$ & $\mathrm{P}^{* * * * *}$ \\
\hline
\end{tabular}

*Valor máximo permitido IN no 11 de 2000 (BRASIL, 2000); **Atividade diastática; ***Condutividade Elétrica; $* * * *$ Positivo $\mathrm{e} * * * * *$ Negativo.

Os teores de umidade e cinzas das amostras de méis apresentaram-se adequados em relação às normas brasileiras para o mel puro. Em relação à atividade diastática, todos os resultados foram inferiores a $15 \mathrm{mg} \mathrm{kg}^{-1}$ também atendendo as especificações da Legislação (BRASIL, 2000).

Os resultados de condutividade elétrica nas amostras variaram de 350,5 a $1202 \mu \mathrm{S} \mathrm{cm} \mathrm{cm}^{-1}$. Estes resultados estão próximos aos valores obtidos em outros trabalhos descritos na literatura (MARCHINI, 2005).

Tendo em vista os riscos oferecidos por espécies metálicas em alimentos de uma forma geral, a ANVISA torna obrigatório o monitoramento de diversos metais em todos os produtos alimentícios embalados e/ou processados. A concentração de $\mathrm{Zn}$ e $\mathrm{Cu}$ encontrados nas amostras está de acordo com os valores máximos permitidos em mel segundo Legislação Brasileira (Tabela 2) (BRASIL, 1998).

TABELA 2 - Resultados das determinações da concentração de metais (média \pm desvio-padrão, $n=3$ ) obtidos nas amostras de méis de diferentes regiões brasileiras.

\begin{tabular}{ccccccc}
\hline \multirow{2}{*}{ Amostra } & $\mathbf{N a}$ & $\mathbf{K}$ & $\mathbf{M g}$ & $\mathbf{Z n}$ & $\mathbf{C u}$ & $\mathbf{M n}$ \\
\cline { 2 - 7 } & \multicolumn{7}{c}{$\left.\mathbf{m g ~ k g}^{-1}\right)$} & & & \\
\hline $\mathbf{A 1}$ & $28,2 \pm 0,4$ & $60,6 \pm 1,5$ & $45,5 \pm 0,5$ & $* \mathrm{ND}$ & $0,40 \pm 0,04$ & $0,70 \pm 0,02$ \\
\hline $\mathbf{A 2}$ & $38,5 \pm 0,1$ & $59,4 \pm 0,3$ & $104,1 \pm 1,5$ & $0,69 \pm 0,03$ & $0,45 \pm 0,01$ & $1,8 \pm 0,07$ \\
\hline $\mathbf{A 3}$ & $54,6 \pm 2,0$ & $60,3 \pm 0,5$ & $52,1 \pm 0,5$ & $* \mathrm{ND}$ & $* \mathrm{ND}$ & $3,2 \pm 0,2$ \\
\hline $\mathbf{A 4}$ & $41,3 \pm 1,8$ & $61,7 \pm 1,7$ & $61,7 \pm 2,5$ & $* \mathrm{ND}$ & $* \mathrm{ND}$ & $9,2 \pm 0,5$ \\
\hline $\mathbf{A 5}$ & $54,6 \pm 1,2$ & $41,2 \pm 2,0$ & $90,4 \pm 2,1$ & $* \mathrm{ND}$ & $* \mathrm{ND}$ & $0,60 \pm 0,4$ \\
\hline $\mathbf{A 6}$ & $53,7 \pm 0,5$ & $59,4 \pm 2,5$ & $81,5 \pm 1,7$ & $* \mathrm{ND}$ & $3,4 \pm 0,8$ & $0,70 \pm 0,8$ \\
\hline $\mathbf{A 7}$ & $53,2 \pm 1,0$ & $58,8 \pm 1,8$ & $84,3 \pm 0,5$ & $* \mathrm{ND}$ & $3,1 \pm 0,5$ & $1,0 \pm 0,5$ \\
\hline VMP $^{*}$ & 60 & 990 & 60 & 2 & 10 & 3,8 \\
\hline
\end{tabular}

*Valores máximos permitidos pela Tabela Brasileira de Composição de Alimentos (LIMA, 2006) e pela Portaria no 685 de 1998 (Cu) (BRASIL, 1998).

Os minerais, embora presentes em pequenas quantidades no mel, são considerados importantes do ponto de vista nutricional por serem encontrados na forma diretamente assimilável (FRIAS; HARDISSON, 1992). A concentração de Na, K, Zn e Mg apresentou uma grande variação entre as amostras avaliadas. A concentração de sódio está próxima aos valores indicados pela Tabela Brasileira de Composição de Alimentos, enquanto as concentrações de $\mathrm{K}$ e Mg estão acima dos valores estipulados. No caso do zinco, as concentrações encontradas estão abaixo dos valores da 
Tabela Brasileira de Composição de Alimentos (LIMA, 2006). Isto pode ser atribuído devido à composição mineral dos méis brasileiros variarem de acordo com a origem floral, características do solo, clima e fatores relativos às abelhas (MARCHINI et al., 2005).

O Brasil dispõe de uma grande diversidade de espécies de abelhas, que têm apresentado potencial para a produção de mel, principalmente por estarem adaptadas às condições climáticas e florísticas. Contudo, a diversidade de espécies e o amplo espectro de fontes florais, resultam em dificuldades para a definição de padrões de qualidade do mel. Dessa forma, a caracterização físicoquímica destes produtos é de extrema relevância, bem como, o estabelecimento de padrões, com o objetivo de melhorar a qualidade do mel produzido e dar garantias do produto ao consumidor brasileiro.

\title{
4 Conclusão
}

Todas as amostras analisadas apresentaram algum tipo de inconformidade com as especificações exigidas para o controle de qualidade do mel no Brasil, demonstrando um alto índice de reprovação das amostras de méis avaliadas. Neste contexto, os resultados sugerem a importância do controle de qualidade dos méis produzidos no Brasil no intuito de evitar possíveis fraudes e/ou contaminações, pois a produção de mel no país vem apresentando um contínuo crescimento, o que torna importante a fiscalização deste produto.

\section{Agradecimentos}

Os autores agradecem a Universidade de Cuiabá (UNIC) e ao Laboratório de Análises de Contaminantes Inorgânicos (LACI) do Departamento de Química da Universidade Federal de Mato Grosso (UFMT).

\begin{abstract}
This work aimed to determine the physicochemical parameters and the metals concentration in honeys from different Brazilian regions and compare the results with the current legislation. For this purpose, seven samples from different Brazilian regions of Brazil were collected and made the following determinations: $\mathrm{Na}, \mathrm{K}, \mathrm{Mg}, \mathrm{Mn}, \mathrm{Zn}, \mathrm{Cu}$, humidity, ash, electrical conductivity, free acidity, diastase activity, of Lund, Fiehe and Lugol reactions. The free acidity, humidity, ash and diastatic activity were agreement with the specifications required by Brazilian legislation. In the Lugol test, all samples tested positive, ie, detected the presence of dextrin and starch. In Fiehe reaction, five samples were positive indicating overheating and / or the presence of sugar syrup. Lund tests were positive indicating the presence of albuminous substances. For all samples, the concentrations of metals were agreement with the values allowed by Legislation and literature for honeys. In this context, the results suggest that honey production in Brazil must be accompanied by
\end{abstract}


strict supervision and quality control to ensure a product free from adulteration, fraud and contamination.

Key-words: honey; physicochemical parameters; metals.

\section{Referências}

ALVES, R. M. O.; CARVALHO, C. A. L.; SOUZA, B. A.; SODRÉ, G. S.; MARCHINI, L. C. Características físicoquímicas de amostras de mel de melipona mandacaia smith (hymenoptera: apidae). Ciência tecnológica alimentícia, v. 25, n. 4, p. $644-650,2005$.

AROUCHA, E. M. M.; OLIVEIRA, A. J. F.; NUNES, G. H. S.; MARACAJÁ, P. B.; SANTOS, M. C. A. Qualidade do mel de abelha produzidos pelos Incubados da iagram e comercializado no Município de Mossoró/RN. Revista Caatinga, v. 21, n. 1, p. 211-217, 2008.

ARRUDA, C. M. F; MARCHINI, L. C.; SODRÉ, G. N.; MORETTI, A.C. C. C. Características físico-químicas de amostras de méis de apis mellifera 1., 1758 (hymenoptera, apidae) da região da chapada do araripe, município de Santana do Cariri, Estado do Ceará. Boletim de Indústria Animal, v. 61, n. 2, p. 141-150, 2004.

BOGDANOV, S. Honey quality and international regulatory standards: review by the international honey commission. Bee World, v. 80, n. 2, p. 61-69, 1999.

BRASIL. Ministério da Agricultura, Pecuária e Abastecimento. Instrução Normativa $\mathrm{n}^{\circ} 11$ de 20 de outubro de 2000. Regulamento Técnico de Identidade e Qualidade do Mel. Diário Oficial [da República Federativa do Brasil], Brasília, 23 de outubro de 2000.

BRASIL, Ministério da Saúde. Portaria no 685 de 27 de agosto de 1998. Princípios Gerais para o Estabelecimento de Níveis Máximos de Contaminantes Químicos em Alimentos - Limites máximos de tolerância para contaminantes inorgânicos. Diário Oficial [da República Federativa do Brasil], Brasília, 28 de agosto de 1998.

CANO, C. B.; NAGATO, L. A. F.; DURAN, M. C. et al. Açúcares e produtos correlatos. In: INSTITUTO ADOLFO LUTZ. Métodos físico-químicos para análise de alimentos. 4 ed. Brasília: ANVISA, Cap.7, p.321-343, 2005.

CRANE, E. O livro do mel. 2 ed. São Paulo: Nobel, 1983.

FRÍAS, I.; HARDISSON, A. Estudio de los parámetros analíticos de interés en la miel. II: Azúcares, cenizas y contenido mineral y color. Alimentaria, v. 28, n. 235, p. 41-43, 1992.

LACERDA, J. J. J.; SANTOS, J. S.; SANTOS, S. A.; RODRIGUES, G. B.; SANTOS, M. L. P. Influência das características físico-químicas e composição elementar nas cores de méis produzidos por Apis Melífera no sudoeste da Bahia utilizando análise multivariada, Química Nova, v. 33, n. 5, p. 1022-1026, 2010.

LASCEVE, G.; GONNET, M. Analyse par radioactivation du contenu minéral d'un miel. Possibilité de préciser son origine géographique. Apidologie, v. 5, p. 201-223, 1974.

LEAL, V. M.; SILVA, M. H.; JESUS, N. M. Aspecto físico-quimico do mel de abelhas comercializado no município de Salvador- Bahia. Revista Brasileira de Saúde e Produção Animal, v 1, n.1, p.14-18, 2001.

LIMA, D. M. et al. Tabela brasileira de composição de alimentos/NEPA-UNICAMP. T113 Versão II. Campinas:

NEPA-UNICAMP, 105 p., 2006. Disponível em: <http:/www.unicamp.br/nepa/taco>, acesso em 18/11/2011.

MARCHINI, L. C.; MORETTI, A. C. C. C.; OTSUK, I. P. Análise de agrupamento, com base na composição físicoquímica de amostras de méis produzidos por Apis mellifera L. no Estado de São Paulo. Ciência e Tecnologia de Alimentos, v. 25, n. 1, p. 8-17, 2005.

MENDES, B. A.; COELHO, E. I. Considerações sobre características de mel de abelhas Análises e critérios de inspeção. Informe Agropecuário, v. 9, p. 56-67, 1983.

PINTO, J. P. A.; RUDGE, A. C. Análise do mel comercializado no Estado de São Paulo. Veterinária e Zootecnia, v. 3, p. 77-83, 1991. 
SILVA, C. L.; QUEIROZ, A. J. M.; FIGUEIREDO, R. M. F. Caracterização físico-química de méis produzidos no Estado do Piauí para diferentes floradas. Revista Brasileira de Engenharia Agrícola e Ambiental, v. 8, n. 2-3, p. 260265, 2004.

WIESE, H. Apicultura: Novos Tempos. Guaíba: Editora Agropecuária Ltda. 2000.

WHITE JÚNIOR, J. W. The role of HMF and diastase assays in honey quality evaluation. Bee World, v. 75, n. 3, p. 104-107. 1994.

WHITE JUNIOR, J. W. Methods for determining carbohydrates, hydroxymetilfurfural and proline in honey; collaborative study. Journal of the Association of Official Analytical Chemists, v. 62, n. 3, p. 515-526, 1979.

Submetido em 08 dez 2011, Aceito para publicação em 04 out 2012. 